\title{
A Superação do Subdesenvolvimento e a Via da Democracia Deliberativa*
}

\section{Overcoming Underdevelopment and the Path of Deliberative Democracy}

\author{
Guilherme Spinato Morlin** \\ Ronaldo Herrlein Júnior***
}

\begin{abstract}
Resumo: Este artigo apresenta uma análise da relação entre a democracia e a concepção normativa do desenvolvimento como processo endógeno. $\mathrm{O}$ desenvolvimento endógeno, alternativa de superação do subdesenvolvimento, é um processo intencional de transformação social identificado com os valores e a cultura da população. A deliberação emerge como forma legítima de determinação das finalidades do desenvolvimento. Neste artigo, buscou-se compreender em que medida instituições que efetuem os princípios da democracia deliberativa constituem um arranjo social possível e funcional ao desenvolvimento. A relação entre desenvolvimento endógeno e democracia deliberativa é vista sob a perspectiva teórica e também a partir dos resultados de experiências reais de procedimentos deliberativos. Esses procedimentos apresentaram resultados positivos sobre redistribuição de recursos, qualificação de políticas públicas e mudança nas relações de poder, embora sejam limitados pela escala de atuação das instituições e pela dependência de processos políticos mais intensos.
\end{abstract}

Palavras-chave: Desenvolvimento. Democracia deliberativa. Subdesenvolvimento.

\begin{abstract}
This article presents an analysis of the link between democracy and normative conception of development as an endogenous process. Endogenous development is an alternative to overcome underdevelopment which consists of an intentional process of social change identified with values and culture of the population. Deliberation appears as a legitimate way of determining the purposes of development. This study sought to understand to what extent institutions which perform the principles of deliberative democracy constitute a social arrangement feasible and functional for the development. The relationship between endogenous development and deliberative democracy is seen from a theoretical perspective and also from the results of actual deliberative procedures. Deliberative procedures showed positive impacts on distribution, improvement of public policies and change in power relations, although those results were restrained by the institution's scale of operation and the dependence of more intense political processes.
\end{abstract}

Keywords: Development. Deliverative democracy. Underdevelopment.

JEL Classification: O17; O10.

* $\quad$ Artigo apresentado na Segunda Reunião Ibero-Americana de Socioeconomia, ocorrida em Porto Alegre, Rio Grande do Sul, em novembro de 2015.

** Mestrando em Economia da Indústria e da Tecnologia pela Universidade Federal do Rio de Janeiro (UFRJ). E-mail: guilherme.morlin@gmail.com

*** Doutor em Economia pela Universidade Estadual de Campinas (Unicamp). Professor do Departamento de Economia e Relações Internacionais da Universidade Federal do Rio Grande do Sul (UFRGS).E-mail: ronaldoh@ufrgs.br 


\section{1 lntrodução}

A noção de desenvolvimento incorpora uma visão positiva a respeito do homem enquanto lhe atribui a faculdade de transformar o meio que o envolve. $\mathrm{O}$ desenvolvimento pode ser entendido, portanto, como uma progressão histórica de libertação do homem através da ampliação da sua capacidade de ação e criação; como o empenho da capacidade criativa no enriquecimento do universo de valores e a sua difusão em amplos segmentos da sociedade. Em perspectiva histórica, a trajetória do homem no domínio do mundo exterior - a ampliação de sua capacidade de controlar e agir sobre a natureza - revela-se como o caminho da conquista do homem por ele mesmo, desafio final às suas aspirações de ser superior (FURTADO, 1984, 2013a).

A progressão do conjunto de valores acessíveis à coletividade depende da geração dos alicerces desse processo, localizados no crescimento do excedente de recursos. Modernamente, o esforço em favor da expansão do excedente é traduzido no processo de acumulação - emprego sistemático do excedente no desenvolvimento das forças produtivas e na intensificação da divisão social do trabalho, tendo como consequência a geração de maior excedente. Contudo, apesar de o progresso material consistir num requisito para o desenvolvimento, a acumulação capitalista possui uma relação ambígua com esse processo, impondo obstáculos a sua plena realização. Essas limitações só foram superadas (pelo menos parcialmente) quando conflitos sociais emergentes das relações capitalistas de produção promoveram significativas transformações na estrutura social. Assim, o desenvolvimento foi atingido por um grupo de nações não de modo espontâneo, mas quando elas foram mobilizadas por um projeto de sociedade.

Por outro lado, em um grupo de nações que acessaram a civilização industrial $^{1}$ de modo indireto, os encadeamentos históricos legaram uma condição de subdesenvolvimento. Nesses países, o excedente crescente foi empregado de modo a fortalecer as relações sociais previamente estabelecidas, em um padrão de acumulação incapaz de promover as transformações necessárias ao desenvolvimento. Assim, persiste em um grupo de países um quadro de dependência cultural, heterogeneidade social e exclusão de considerável parcela da população. A solução sugerida é a busca por um desenvolvimento endógeno: a retomada de um projeto de construção nacional enraizado nos valores da população, que é responsável por determinar as prioridades do desenvolvimento. Dessa forma, propõe-se que a criação e o fortalecimento de instituições que efetuem os princípios da de-

1 Com o conceito de civilização industrial, Celso Furtado descreve a civilização surgida da Revolução Burguesa, transformação política que conduz à ascensão da burguesia e produz rupturas institucionais, e da Revolução Científica, processo de difusão da racionalidade e exacerbação do progresso técnico, consolidada na Europa do século XIX e difundida de diferentes maneiras pelo mundo. 
mocracia deliberativa possibilitem a definição dos objetivos do desenvolvimento e das estratégias para persegui-los.

Para além desta introdução, o artigo possui três seções de desenvolvimento, seguidas pelas considerações finais. Na segunda seção, expõe-se uma breve revisão da problemática do subdesenvolvimento, compreendido enquanto processo histórico implicado em relações sociais. Na terceira seção, apresenta-se a concepção de desenvolvimento endógeno, relacionada ao problema do subdesenvolvimento e também aos limites do desenvolvimento capitalista. Na quarta seção, é estabelecida a relação com a democracia deliberativa, que se mostra essencial para a noção apresentada de desenvolvimento. Finalmente, são apresentadas sintéticas considerações finais.

\section{Processo Histórico de Subdesenvolvimento}

Para se conhecer os determinantes da persistência histórica do subdesenvolvimento, é preciso analisá-lo como componente de um todo em movimento, um elemento do sistema econômico mundial produzido pelo capitalismo industrial (FURTADO, 1980). A constituição do sistema econômico mundial sustentou-se na transformação das estruturas sociais e no processo de modernização do estilo de vida. Da interação entre esses dois fenômenos e da prevalência de um deles, derivam dois processos históricos discrepantes na época contemporânea: o desenvolvimento e o subdesenvolvimento.

Os países denominados centrais, ${ }^{2}$ dos quais partiram os impulsos dinamizadores da economia mundial nos séculos XIX e XX, foram o ambiente gerador da revolução industrial. Furtado (1983, 1984, 2008) distingue duas etapas no processo histórico observado nesses países. Na primeira, o resultado das revoluções burguesas e das revoluções tecnológicas reestrutura as relações sociais de modo a ampliar a acumulação e seu impacto na sociedade. A acumulação no centro dá-se com um contínuo e intenso avanço tecnológico, que sustenta a sequência da acumulação no longo prazo (RODRIGUEZ, 2009). A tendência observada nessa etapa é de aumento da quantidade de capital por trabalhador. Apesar do caráter predominantemente poupador de mão de obra do progresso técnico, persiste uma

2 A diferenciação centro-periferia surge do modo como grupos de países assimilaram a civilização industrial. Originada na Europa e estendida por meio das migrações para regiões temperadas, a civilização industrial engendrou uma divisão internacional do trabalho, que culminou na formação de um sistema econômico global. Os países periféricos foram aqueles que assimilaram a civilização industrial de forma indireta, por meio de sua participação no comércio internacional. Nesses países, ocorreram alterações na demanda por bens finais, sem anteriores transformações em seu conjunto de relações sociais, nem em seu sistema produtivo. Nesse processo, não absorvem apenas padrões de consumo, mas valores e ideologias, assumindo uma posição dependente no sistema econômico mundial (FURTADO, 2008). 
tendência de escassez desta, o que promove uma elevação gradual dos salários. Ao mesmo tempo, o progresso tecnológico traduz-se também na diversificação do conjunto de bens de consumo final, fator convergente com o crescimento dos salários e o decorrente robustecimento do mercado de consumo. Posteriormente, em uma segunda etapa, a organização das massas trabalhadoras e sua crescente participação nas estruturas de poder conduziriam a uma maior homogeneidade social. Na verdade, a intensa acumulação e a concentração industrial e financeira - resultantes da busca de ganhos de escala e de conglomeração - convertem o trabalhador individual em partícipe de "grupamentos sociais estruturados", fontes de novas formas de poder que proporcionam a transferência dos conflitos econômicos para a esfera política (FURTADO, 2013b, p. 209).

Com esse referencial simplificado, pode-se discorrer sobre o processo antípoda: o subdesenvolvimento. A propensão expansiva do capitalismo industrial procedeu, gradualmente, à formação de um sistema econômico mundial, ${ }^{3}$ integrando as economias periféricas por meio do comércio internacional e da transferência de capitais. O investimento realizado dentro das economias centrais era o principal fator dinamizador da economia mundial, operando transformações nas economias periféricas. A inserção da periferia na divisão internacional do trabalho ocorreu, portanto, a partir de seu vínculo com o centro e não do desenvolvimento de suas forças produtivas (FURTADO, 1980). As relações tradicionais de dominação vigentes nesse grupo de países foram apenas parcialmente modificadas, conforme seguia a apropriação de um excedente crescente, originado pela inserção comercial. Na maioria dos casos, a considerável ampliação do excedente reforçava o sistema de dominação social, acrescentando-lhe alianças externas (FURTADO, 2008).

Mesmo assim, mutações importantes foram promovidas, como a elaboração de uma infraestrutura de transportes, com o suporte financeiro e conforme os interesses das economias centrais, mas também com o apoio político dos grupos dominantes locais. Esses investimentos aprofundavam a divisão internacional do trabalho e seus resultados concentravam-se no setor exportador, enquanto nos demais setores a produtividade persistia baixa e estagnada. As economias periféricas especializaram-se na exportação de certos produtos, com mínimos aumentos de produtividade decorrentes de progresso tecnológico, mas com ganhos derivados da realocação de recursos produtivos no setor exportador - como a expansão da fronteira agrícola. O crescimento econômico da periferia tem insignificante impacto sobre sua estrutura social. O lento ritmo da acumulação no conjunto da econo-

3 A força expansionista do capitalismo industrial causou modificações de três formas distintas, consolidando a tendência de unificar a civilização material em todo o planeta: o primeiro fenômeno foi a amplificação e complexificação do núcleo industrial inicial; o segundo foi o deslocamento de milhões de europeus para novos territórios, de baixa densidade demográfica; por fim, o terceiro foi a expansão das relações comerciais que conduziria à constituição de uma divisão internacional do trabalho (FURTADO, 1980). 
mia mantém uma limitada expansão da demanda pela força de trabalho, exígua quando comparada ao acréscimo da oferta. Por conseguinte, grandes parcelas da mão de obra ocupam-se em setores de baixa produtividade e reduzida remuneração. Nesse quadro de subemprego, consolida-se a heterogeneidade social, que é característica marcante do subdesenvolvimento (FURTADO, 1980).

A especialização assegurou o crescimento do excedente, embora este tenha sido muitas vezes acompanhado pela simplificação do sistema produtivo (FURTADO, 1980). Dada sua inserção internacional subordinada - figurada pelo modelo agrário-exportador - e os vínculos externos de seus grupos dominantes, os países periféricos assimilaram valores e ideais disseminados em países do centro e, a partir disso, procedem à importação de padrões de consumo e de padrões tecnológicos relacionados. Assim, uma minoria da população efetua um processo de diversificação da demanda interna por bens finais, suprida por meio de importações, em um contexto de imobilismo social. A modernização do consumo - esse conjunto de transformações de sofisticação da demanda - compromete o uso produtivo do excedente em favor da "[...] exacerbação prematura do consumo imitativo [...]" (RODRIGUEZ, 2009, p. 412). Consequentemente, a demanda de uma minoria da população obtém um dinamismo incoerente com a estrutura produtiva local e que somente pôde prosseguir conforme aumentavam as exportações. "Com efeito: $\mathrm{O}$ excedente retido na periferia desempenhará papel fundamental no processo de aculturação desta, operando como vetor dos valores culturais do núcleo industrial em expansão" (FURTADO, 1980, p. 86). Nessa concepção, a dependência cultural torna-se um elemento central na explicação do processo de subdesenvolvimento.

É certo que a introdução de diversos produtos industrializados na cesta de consumo modifica a estrutura da economia, através da necessidade de produtos ou serviços locais complementares. Isso se traduziu em uma industrialização restringida, isto é, em um crescimento industrial limitado e localizado setorialmente. Essa indústria estabelecia um vinculo direto com o mercado interno - ao contrário das indústrias relacionadas aos produtos de exportação -, embora sua formação fosse, geralmente, de iniciativa de grupos comerciais importadores. Seu crescimento teve significativo impacto sobre a economia local e constituiu o ponto de partida das indústrias de substituição de importações nos períodos de desequilíbrio no setor externo. Uma vez que a elasticidade-renda da demanda pelos bens industrializados era elevada e que o aumento das exportações, condição para o crescimento das importações, encontrava obstáculos, especialmente na maior rigidez do sistema produtivo, existia uma tendência ao desequilíbrio externo, que foi reforçada no período de crise do sistema de divisão internacional do trabalho (conjunto de crises e tensões internacionais no período entre guerras). Nessas circunstâncias, a alternativa foi substituir as importações mediante a industrialização. Segue-se, então, uma dinâmica na qual as importações são responsáveis por 
diversificar a oferta interna - e com isso, modernizar os padrões de consumo. A industrialização emerge como segunda opção no suprimento da demanda interna, sendo sempre mediada pela modernização, isto é, a absorção dos padrões de consumo diferenciados do centro (FURTADO, 1980; RODRIGUEZ, 2009).

Conforme se complexifica o grau de substituição de importações, aumenta a dependência de tecnologias importadas. Deve-se ressaltar que as profundas conexões entre o progresso técnico e o contexto social que o produz são essenciais na explicação do subdesenvolvimento. A industrialização periférica se dá por meio de técnicas geradas nos países de acumulação mais avançada, que têm alta densidade de capital e propiciam baixa criação de empregos. Portanto, elas mostram-se inadequadas ao estágio de acumulação em que a economia periférica se encontra, usando mais intensivamente seus recursos escassos na forma de bens de capital e prejudicando, consequentemente, o ritmo de absorção da mão de obra. A introdução de tecnologia estrangeira inibe a elaboração endógena de técnicas adequadas à estrutura social, problema consolidado nas estratégias substitutivas (FURTADO, 1984). Além disso, tais técnicas compõem processos produtivos de grande escala, excessivas quando comparadas ao tamanho dos mercados formados na periferia. Por conseguinte, a capacidade produtiva ficará subocupada, e, por isso, a produtividade do trabalho estará sempre abaixo do seu potencial. Esses elementos inter-relacionados que qualificam a industrialização periférica provocam, em conjunto, a vastidão do subemprego estrutural. Ao mesmo tempo, os trabalhadores, donos de uma consciência de classe construída com lentidão, não conseguem organizar um poder sindical capaz de prover um conteúdo social ao crescimento econômico. Sem aumento dos salários, persistem as grandes desigualdades sociais (FURTADO, 2008).

A ascensão de grupos burgueses na periferia, que utilizam o excedente para ampliar sua própria esfera de ação, reproduz o controle do poder político experimentado pela burguesia europeia. No entanto, as consequências no plano político são muito diferentes. A burguesia periférica não procede à profunda recriação das relações sociais como no centro, mas mantém as arcaicas estruturas preexistentes (FURTADO, 2008). "De uma ou outra forma, a massa da população é mantida sob tutela: a participação no processo político da massa assalariada faz-se sob o controle de grupos que integram a estrutura tradicional de poder" (FURTADO, 2008, p. 122).

Vale ressaltar que diferentes formas de autoritarismo foram observadas frequentemente nas nações periféricas, reprimindo o potencial criador dos conflitos sociais e impossibilitando a pressão pela valorização do trabalho. Muitas vezes, conflitos sociais foram vistos como desperdício de energia, como impeditivos no avanço do crescimento econômico. Então, o autoritarismo emergiu como estrutura de poder capaz de proceder à rápida industrialização, conduzindo a sociedade 
a patamares superiores de acumulação. A submissão da democracia a objetivos abstratos, como o crescimento econômico e a expansão das exportações e dos investimentos, é justificada por meio de um mito, de uma injustificada certeza de que os padrões de vida da população dos países desenvolvidos estão acessíveis às nações periféricas e de que os esforços mobilizados em nome do crescimento econômico se traduzirão automaticamente em desenvolvimento (FURTADO, 1974). Apesar de o núcleo da crítica a essa crença infundada originar-se na percepção de que os recursos naturais não comportam a extensão mundial do padrão de consumo de países centrais, a crítica pode ser compreendida em uma perspectiva mais ampla, na medida em que questiona o próprio conteúdo e os resultados sociais do progresso econômico perseguido por nações periféricas. O mito do desenvolvimento econômico é um desdobramento ideológico das relações de poder presentes em sociedades subdesenvolvidas e atua como reforçador dessas relações. ${ }^{4}$ Nesse contexto, o autoritarismo atua como "[...] uma arma repressora das forças sociais que a industrialização dependente não consegue canalizar de modo construtivo" (FURTADO, 2008, p. 110). Com isso, reprime a constituição de respostas genuínas aos problemas locais, impede a manifestação da criatividade no plano social para acomodar conflitos e produzir novos resultados e, assim, bloqueia o desenvolvimento.

Em resumo, o subdesenvolvimento pode ser compreendido como a disparidade entre o atraso na acumulação e o dinamismo da demanda em certo país. A economia subdesenvolvida se industrializa e supera a rígida estrutura produtiva preexistente. Contudo, essa adaptação está vinculada à sustentação do processo de modernização do consumo dos segmentos de renda elevada, em geral aprofundando (ou mantendo) as desigualdades. Consequentemente, "[...] o desenvolvimento das forças produtivas em condições de dependência não engendra as transformações sociais que estão na base da valorização da força de trabalho" (FURTADO, 2008, p. 98). Persiste o caráter antissocial do subdesenvolvimento, conjugado com a dependência cultural e com o reforço do poder de elites identificadas com os países centrais. A acumulação, por si, não é capaz de reverter esse quadro, uma vez que os principais obstáculos ao desenvolvimento se encontram na esfera social.

$4 \quad$ O mito legitima o enfrentamento de quaisquer sacrifícios, como a destruição de culturas tradicionais, a submissão da democracia, o rompimento com valores avançados e a degradação do meio ambiente em favor do crescimento (FURTADO, 1974). 


\section{A Alternativa do Desenvolvimento Endógeno}

Diante da persistência da condição de subdesenvolvimento e da busca por sua superação, torna-se necessário desvincular a concepção de desenvolvimento de quaisquer mitos de progresso ou modernização que favoreçam a preservação das relações de poder vigentes e das desigualdades sociais. A via do desenvolvimento endógeno defendida por Furtado (1984) consiste num processo intencional de transformação social identificado com os valores e a cultura da sociedade, que amplia a capacidade de criação da coletividade e difunde os resultados do crescimento e do progresso imaterial em amplos segmentos da população. Para alcançar o desenvolvimento assim concebido, é preciso que a sociedade seja capaz de definir de modo autônomo suas próprias finalidades e as trajetórias para persegui-las. Essa concepção explicita uma noção de propósito: "mais do que transformação, o desenvolvimento é invenção, comporta um elemento de intencionalidade [...]" (FURTADO, 1984, p. 105, grifos no original). Portanto, a superação das deformações engendradas pelo acesso indireto à civilização industrial torna-se possível mediante o reencontro da criatividade no nível das finalidades - dos objetivos almejados -, contornando as iniquidades do subdesenvolvimento e estancando a dependência cultural. Em suma, a noção de desenvolvimento endógeno aborda tal processo como um projeto aberto - não completamente definido - cujas conquistas devem, em sentido normativo, estar contidas nas aspirações da coletividade, necessitando, consequentemente, de um mecanismo democrático abrangente para a definição e ordenação das prioridades. Trata-se de um projeto fundamentado por amplo consenso social.

Essa visão compreende uma riqueza multidimensional a respeito do desenvolvimento, que o relaciona à realização das potencialidades dos indivíduos (HERRLEIN JÚNIOR, 2014). Com efeito, "[...] sociedades são consideradas mais desenvolvidas na medida em que nelas o homem mais cabalmente logra satisfazer suas necessidades, manifestar suas aspirações e exercer seu gênio criador" (FURTADO, 1984, p, 105). A partir da compreensão de que o desenvolvimento se caracteriza no plano da criação de valores materiais e imateriais, e na difusão destes, refuta-se qualquer perspectiva unilateral do processo, especialmente ao valorizar-se o plano cultural como primordial para o desenvolvimento. Nessa perspectiva, a renda nacional (ou o PIB) não merece a primazia como indicador de bem-estar. ${ }^{5}$

5 Sen (2010) ressalta que a avaliação do desenvolvimento é um exercício de escolha social e não deve fundamentar-se em um sistema de valores implícito, como ocorre quando a renda é o indicador escolhido para essa avaliação. Em um esquema avaliativo com valores explicitados, a contribuição da renda e da riqueza ao desenvolvimento deve ser apreciada segundo as capacitações promovidas por elas, ou seja, o conjunto de liberdades fruídas pelos indivíduos por meio da renda. Herrlein Júnior (2014) apresenta a abordagem das capacitações de Sen como um marco avaliativo compatível com a proposta do desenvolvimento endógeno. 
A partir do momento em que se ordenam previamente as necessidades sociais a satisfazer, o problema do desenvolvimento deixa de ser o de maximizar uma taxa abstrata de PIB, para ser o de minimizar os custos sociais requeridos para atingir os objetivos definidos. As comparações intertemporais de graus de desenvolvimento passam a ser feitas em termos de indicadores precisos: expectativa de vida, mortalidade infantil, alfabetização, tempo médio de vida escolar, incidência negativa de doenças mentais, atividade cultural, criatividade nas artes e nas ciências, tempo de trabalho não pago (transporte, etc.), qualidade e quantidade da habitação, tempo e qualidade do ócio, participação na vida política, acesso à informação, contatos com populações estrangeiras, etc. (FURTADO, 1975, p. 68, grifo do autor).

A respeito da importação de padrões tecnológicos, vale ressaltar que não é possível refutar a relevância da técnica e da acumulação produtiva como formas de ampliar a capacidade de ação da coletividade. Consequentemente, torna-se indispensável usar desses mecanismos preservando a autonomia na definição dos objetivos perseguidos. É preciso, então, descobrir como usufruir das oportunidades oferecidas pela moderna tecnologia como instrumento na busca pela homogeneização social, averiguando as possibilidades de endogeneização do desenvolvimento.

Na observação de estratégias na busca da endogeneização, Furtado (1984) localiza três modelos de experiências. O primeiro citado é a coletivização dos meios de produção, baseada no controle coletivo das atividades produtivas. Essa estratégia visa destruir as bases das estruturas de poder que sustentam o subdesenvolvimento e substituir o sistema de mercado por uma racionalidade mais abrangente. Entretanto, esbarra nas dificuldades de promover a acumulação num contexto de grandes demandas coletivas. Ao mesmo tempo, se o planejamento ocorrer de forma centralizada, essa forma social pode promover uma elite burocrática autoritária e cada vez mais distante dos interesses da maioria da sociedade. Outra limitação é a ausência de um sistema de incentivos e de iniciativa descentralizada para favorecer a produção, o crescimento da produtividade e a acumulação de modo geral. Também existem problemas no plano das relações externas, na obtenção da tecnologia e do financiamento necessários, sem comprometer o propósito inicial.

Outra via seria a do aumento do grau de autonomia externa, através de uma posição ofensiva no mercado internacional. Essa estratégia exportadora requer que a nação mantenha-se na vanguarda das inovações em produto, obtenha competitividade no mercado internacional e, ainda assim, assegure um efeito indutor interno. A formação de grandes empresas nacionais pode ser um veículo dessa trajetória. Contudo, países que adotam essa estratégia correm o risco de sucumbir 
ao fortalecimento de estruturas estatais autoritárias, ${ }^{6}$ o que perverteria o processo de endogeneização (FURTADO, 1984). A endogeneidade nesse modelo de experiência reside no ganho de autonomia nas relações externas, sendo superadas a dependência e a passividade estabelecidas pela divisão internacional do trabalho. Ao mesmo tempo, a acumulação reverte-se em melhoria do padrão material de vida da população. Em consequência, o país assume uma posição ofensiva no comércio internacional, podendo ingressar na vanguarda do progresso tecnológico e pautar a elaboração dos estilos de vida mundialmente difundidos (FURTADO, 1984).

Contudo, as duas estratégias citadas podem gerar estruturas autoritárias de poder, o que restringe a efetuação do ideal endógeno. Ainda assim, representam um processo parcial de retomada do projeto de construção nacional, rejeitando as referências externas e elevando o patamar da qualidade de vida da população. Contudo, ao considerar-se essa concepção em sua profundidade, torna-se imprescindível a existência de uma democracia mais intensa e abrangente, mais facilmente compatibilizada com o terceiro caminho, apresentado a seguir.

A terceira possibilidade favorável à endogeneização do desenvolvimento é o atendimento de necessidades básicas da coletividade. Consiste na satisfação de um conjunto de necessidades consideradas prioritárias para a maioria da população - até então excluída da partilha dos resultados da acumulação. A intencionalidade política permitiria garantir que parcela do excedente fosse empregada na redistribuição da renda e na expansão e qualificação dos serviços públicos - um exemplo mencionado por Furtado (1984) é a erradicação da pobreza extrema por meio de transferências de renda. Nesse caso, torna-se necessário não apenas mobilizar forças políticas em torno desse projeto, como também adequar a estrutura do sistema produtivo ao crescimento do mercado consumidor e ao encarecimento da mão de obra. Essa mutação econômica é desafiadora e pode representar elevado custo social. A designação política do padrão de distribuição de renda representa o elemento de endogeneidade nesse terceiro caminho.

O objetivo tático tem sido ganhar autonomia na ordenação das atividades econômicas, visando à redução das desigualdades sociais que parece segregar necessariamente a civilização industrial em sua propagação periférica. O objetivo estratégico é assegurar um desenvolvimento que se traduza em enriquecimento da cultura em suas múltiplas dimensões e permita contribuir com criatividade própria para a civilização que se mundializa. A ideia de desenvolvimento endógeno funda-se nesse desejo

6 O sucesso dessa estratégia depende de planejamento rigoroso e de uma elevada taxa de poupança, sendo, por isso, um projeto dificilmente amparado pelos agentes sociais. Como precisa ser conduzido pelo Estado, acaba sendo executado de forma autoritária, o que desvirtua a trajetória de endogeneização (FURTADO, 1984). 
de preservação da própria identidade na aventura comum de unificação do processo civilizatório (FURTADO, 1984, p. 123-124).

Finalmente, Furtado (1984) enumera requisitos importantes para o avanço na trajetória de endogeneização. Primeiramente, é necessário atingir certo grau de autonomia nas relações exteriores, restringindo ao mínimo possível a apropriação externa do excedente. Além disso, exige-se, no âmbito interno, a sustentação de estruturas de poder que previnam o emprego do excedente no processo de modernização, promovam a redução das desigualdades e delimitem objetivos de médio e longo prazos. É preciso, ainda, assegurar a descentralização das atividades econômicas em favor do funcionamento adequado do sistema de incentivos, permitindo a utilização do potencial produtivo. Finalmente, é preciso proporcionar amplo espaço para a criatividade no plano social, permitindo a emergência de novos formatos institucionais, e evitar qualquer processo de demasiada concentração de poder.

A alternativa do desenvolvimento endógeno opõe-se não só ao subdesenvolvimento, mas também à tendência de inversão entre fins e meios presente na civilização industrial. Mesmo nos países centrais, a plena realização do desenvolvimento humano encontra obstáculos nos limites de uma civilização centrada no processo acumulativo e no progresso técnico. Apesar de criar novas condições de produtividade e de geração de riqueza material, e superar barreiras até então intransponíveis à ação humana, a acumulação capitalista tende a subverter as verdadeiras finalidades do desenvolvimento humano e toma seu lugar, movimentando enormes forças produtivas no amparo ao incessante processo de acumulação, confrontando o homem como força estranha e colocando em risco as condições de vida no planeta (MARX, 2011). Ademais, o intenso progresso tecnológico não responde aos anseios de certos segmentos da população, que seguem sem suprir necessidades consideradas básicas, mesmo nos países mais avançados. Desse modo, mercados frequentemente operam como criadores e reprodutores de desigualdades. A criatividade, importante motor da acumulação, é exacerbada, embora de modo indireto e distorcido. Hipertrofiam-se, assim, as áreas da criatividade úteis ao avanço da acumulação, como a tecnologia, enquanto atrofiam-se aquelas menos "produtivas", ainda que vinculadas com a realização da vida humana compreendida como um fim em si mesmo, tais como a investigação filosófica, a pesquisa científica básica, o saber artístico e a constituição de uma consciência crítica (FURTADO, 2008).

O componente intencional do desenvolvimento, presente na alternativa do desenvolvimento endógeno, se perde frente à progressão desordenada desse modelo societário. Dessa forma, a civilização industrial corre o risco de sujeitar-se à autonomização do processo de acumulação, que impõe sua própria dinâmica às possibilidades de progresso social e subordina valores estimados, como 
a autonomia, a liberdade, a criatividade. Ao subordinar fins aos meios, nossa civilização "[...] avança aceleradamente para um despenhadeiro [...]" (FURTADO, 2008, p. 203), no qual a difusão desenfreada da racionalidade leva à destruição da capacidade criadora do homem e a sua desumanização. Essa inversão suprime a escolha social na determinação dos valores substantivos que justificam a produção material e dão significado à vida para os indivíduos sociais (HERRLEIN JÚNIOR, 2014, p. 16).

Compreende-se, então, que a busca pela endogeneidade do desenvolvimento, nesse caso, significa também redirecionar o esforço da atividade social para a perseguição das verdadeiras finalidades do desenvolvimento humano, revertendo a inversão de objetivos protagonizada pelas sociedades contemporâneas. Com horizontes mais amplos que os da acumulação, a sociedade civil é capaz de cultivar e, inclusive, praticar valores para além dos restritos valores do mercado, sendo a esfera política o espaço para construir e promover valores em escala social. A esfera política adquire um espaço crescente na civilização industrial, acomodando conflitos por meio da criação de novas instituições ou formas de organização. É nela, enquanto expressão da canalização da criatividade para determinação dos objetivos, que reside a possibilidade de reencontro das finalidades do desenvolvimento humano (FURTADO, 2008).

\section{A Via da Democracia Deliberativa}

A “[...] endogeneidade não é outra coisa senão a faculdade que possui uma comunidade humana de ordenar o processo acumulativo em função de prioridades por ela mesma definidas" (FURTADO, 1984, p. 108). Os objetivos e a avaliação do desenvolvimento estão inscritos nos requisitos do sujeito, nesse caso, da sociedade, que determina os caminhos de sua própria trajetória. Compreende-se essa concepção normativa do desenvolvimento como inerentemente democrática, pois estabelece que a determinação dos objetivos deve expressar uma vontade coletiva, manifestada por meio de debates públicos mais abrangentes.

Uma vez que o processo de desenvolvimento endógeno não é espontâneo, ele precisa ser provocado politicamente. A participação e o respaldo social são capazes de promover os anseios do cidadão comum e impulsionar a criatividade no plano social, o que permite a formulação de soluções originais aos problemas específicos do subdesenvolvimento. Tais elementos mostram-se, portanto, fundamentais para a efetivação do desenvolvimento endógeno. Isso só se tornaria possível a partir de uma maior participação da população no sistema de decisões (FURTADO, 1984). Contudo, Furtado não impõe maiores condições sobre a qualificação da democracia e da participação, satisfazendo-se com regimes represen- 
tativos e requerendo somente a existência de associações mais ativas que contem com a participação direta dos cidadãos.

Entretanto, as presentes condições das instituições políticas têm se mostrado insuficientes para a conquista do desenvolvimento como processo endógeno. Está claro que a democracia representativa proporciona resultados sociais superiores ${ }^{7}$ frente a regimes não democráticos. Por outro lado, persistem limitações importantes nos formatos existentes de democracia representativa. Os procedimentos de agregação característicos desses regimes são insuficientes na geração de (algo próximo de) consensos sobre estratégias para solucionar problemas econômicos e sociais. Na verdade, eles se fundamentam muito pouco no debate público, e a imensa maioria das decisões é delegada aos representantes eleitos, que são muito fracamente monitorados e influenciados pela população. Convém destacar, ainda, que ao limitar a influência e participação de grupos subordinados econômica e socialmente, os modelos existentes, por si, dificultam a superação das relações de poder anacrônicas vigentes nos países subdesenvolvidos.

Diante desses desafios, propõe-se que a democracia deliberativa contenha os requisitos necessários para a definição social das finalidades do desenvolvimento. A elaboração de instituições de democracia deliberativa busca complementar os regimes representativos existentes, formando novos espaços para tomada de decisão com interação entre diferentes atores sociais. Levando adiante o argumento trabalhado por Furtado, entende-se que a democracia deliberativa cria condições para a definição das finalidades do desenvolvimento, sendo uma forma viável e interessante de buscar a superação do subdesenvolvimento.

A ideia de deliberação é fundada na estima por uma cultura política democrática e na aspiração por maior participação da cidadania nas tomadas de decisão. A defesa do processo de argumentação pública e dos processos discursivos de elaboração de objetivos e estratégias se justifica como mecanismo de geração de decisões legítimas e racionalmente aceitáveis (LUBENOW, 2010). A questão da legitimidade é recolocada nas sociedades contemporâneas, nas quais não se verifica a existência de identidades coletivas amplamente aceitas e a pluralidade de crenças, valores e visões de mundo é reconhecida. Na ausência de uma coesão tradicional ou religiosa, as decisões políticas que regem a sociedade precisam de um fundamento alternativo que permita responder às questões práticas de modo legítimo. É no consentimento racional entre indivíduos que se reconhecem mutuamente como livres e iguais que reside o alicerce para decisões legítimas na

7 Sen (2010) demonstra o papel crucial da democracia n prevenção de calamidades públicas de grandes proporções ao enfatizar que nunca houve uma fome coletiva em um país democrático com imprensa livre. Evans e Heller (2012) apresentam outros pontos positivos da democracia sobre a qualidade de vida da população. De fato, observam-se melhores indicadores de saúde, como expectativa de vida, em países democráticos quando comparados a países de regime autoritário (CALDWELL, 1986; BESLEY; KUDAMATSU, 2006). 
atualidade (WERLE, 2013). Através da deliberação, é possível que indivíduos se aproximem de uma consciência comum a respeito de objetivos e estratégias desejados para solucionar problemas específicos.

A concepção normativa de democracia deliberativa emerge da crítica a duas outras concepções, a republicana e a liberal. ${ }^{8}$ A concepção deliberativa proporciona uma combinação de elementos presentes nos dois modelos analisados, provendo-lhes uma configuração diferente. A concepção liberal compreende a democracia como espaço de produção de um equilíbrio no contexto de uma sociedade constituída por interesses privados diversos e conflitantes entre si. Nessa visão, preferências individuais se manifestam por meio do voto e os processos eleitorais representam a agregação dessas preferências. Como essa composição é orientada pela defesa de interesses individuais, as interações são mediadas por negociações, e não por argumentos. Cidadãos são vistos, nessa visão, como portadores de direito e são protegidos pelo Estado na medida em que atuam segundo os limites da lei. Em contrapartida, a concepção republicana da democracia privilegia a política como processo de constituição da sociedade. Com noções fortes de solidariedade e uma identidade comum, a sociedade civil é responsável pela formação de uma vontade coletiva, através do embate de opiniões em uma comunicação pública orientada ao entendimento mútuo e ao bem comum. É nesse tipo de atuação política que se fundamenta a legitimidade da ação estatal. Finalmente, a concepção normativa da democracia deliberativa traduz uma visão intermediária, na qual se destaca a centralidade do processo comunicativo de formação de opiniões que orientem as decisões políticas, ao mesmo tempo em que é priorizada a preservação de direitos individuais e dos princípios do Estado de direito (HABERMAS, 1995). No entanto, a concepção deliberativa não exige uma cidadania excepcionalmente ativa e com práticas políticas fortemente voltadas ao bem comum, como a concepção republicana. A elaboração de objetivos comuns depende apenas da institucionalização de procedimentos comunicativos, o que possibilita a superação dos mecanismos meramente agregativos de preferências sob hipóteses realistas (HABERMAS, 1995).

Instituições de democracia deliberativa devem ampliar os mecanismos pelos quais as pessoas comuns são capazes de efetivamente influenciar políticas que afetem suas vidas (FUNG; WRIGHT, 2001). Na prática, essas instituições têm se concretizado em procedimentos em que cidadãos participam diretamente das discussões e tomadas de decisão, deliberando geralmente sobre uma temática específica. As instituições deliberativas estão conectadas com o sistema político e com a administração pública, na maioria dos casos em esferas de poder local ou regional. $\mathrm{O}$ formato em que se traduzem essas instituições pode ser identificado como o de "enxertos" na estrutura do Estado, com impactos significativos sobre as

Ver Habermas (1995), Avritzer (2000) e Lubenow (2010). 
políticas públicas (WAMPLER, 2011). Vale dizer, as instituições deliberativas não substituem a institucionalidade representativa convencional e muitas vezes interagem com a representação por meio do levantamento de novas informações ou da canalização de demandas da população manifestadas no espaço participativo (SANTOS; AVRITZER, 2002). O sistema de eleições democráticas, direitos civis e liberdade de expressão é um requisito essencial para tais possibilidades de avanço democrático. A concorrência eleitoral impede a captura permanente do poder por grupos específicos e possibilita o ativismo político de grupos subordinados e da sociedade civil como um todo, assim como oportuniza a realização de discussões públicas mais intensas - e a criação de instituições que centralizem tais discussões além de promover a execução das decisões tomadas (EVANS; HELLER, 2012).

Os procedimentos deliberativos possuem pouca ou nenhuma influência sobre a organização da produção e seu papel sobre a distribuição de recursos é possibilitado pela alocação de recursos públicos ou, em menor grau, através de legislações específicas, que podem impactar de modo diverso no patrimônio de diferentes indivíduos. ${ }^{9}$ Assim, os resultados produzidos por um procedimento deliberativo encontram-se circunscritos a um âmbito específico, o que limita suas consequências econômicas e distributivas.

Existem procedimentos deliberativos organizados em torno das mais variadas temáticas e seus formatos institucionais variam de acordo com a especialização de tema e o contexto político e regional no qual são estruturados. Nesses procedimentos, indivíduos apresentam seus argumentos nos termos em que os demais participantes tenham razões para concordar. O processo de discussão é aberto ao levantamento de novas informações e comporta, ainda, a transformação das opiniões trazidas inicialmente pelos indivíduos, uma vez que sejam confrontadas com o conjunto de argumentos. Nesse tipo de instituição, participantes tendem a votar não em favor da alternativa que conforma seus interesses privados, mas daquela que lhes parece mais razoável (FUNG; WRIGHT, 2001). Ainda assim, a busca pelo consenso - embora, de fato, seja inatingivel - envolve diferentes formas de interações estratégicas e negociações - parte relevante da construção de soluções deliberativas - conduzidas por indivíduos ou por grupos previamente organizados.

Aspectos favoráveis da criação de instituição deliberativas são amplamente reconhecidos e evidenciados, ${ }^{10}$ como o aumento do controle democrático da população sobre a administração pública e o maior monitoramento da ação estatal. Realmente, a ampliação da participação proporciona maior accountability e reduz a cadeia de execução e monitoramento vigente no aparato

$9 \quad$ Exemplos desse último efeito seriam visíveis no cadastramento de propriedades rurais (DONOVAN, 2012) ou em projetos relacionados à urbanização e revitalização de bairros (FAGOTTO; FUNG, 2006), cujos impactos sobre proprietários e inquilinos são distintos.

10 Ver Avritzer (2000), Evans (2003, 2005), Fung (2001, 2003, 2011), Fung e Wright (2001), Santos (2002), para mencionar apenas alguns exemplares entre muitos. 
burocrático (FUNG; WRIGHT, 2001). A possibilidade de um fluxo de informações permite feedback contínuo por parte da população, reduzindo as lacunas da implementação de políticas públicas (EVANS; HELLER, 2012; FUNG; WRIGHT, 2001). Crescem e transformam-se as interações entre sociedade civil e Estado, e a burocracia passa a exercer suas funções de modo distinto, acessando, agora, a complexidade de informações providas pela sociedade e colocando-se, ainda, sob a fiscalização da cidadania. Encontram-se, também, complementaridades entre os esforços da burocracia e da sociedade civil, ${ }^{11}$ incrementando os serviços públicos $\mathrm{e}$, consequentemente, melhorando os indicadores sociais.

Embora não se possa refutar a influência das hierarquias sociais sobre as discussões e decisões, as instituições deliberativas tornam possível o êxito do melhor argumento em detrimento de grupos dominantes. Com efeito, a esfera pública é irrestrita quanto a conteúdos comunicativos e, assim, revela-se um espaço no qual minorias étnicas, mulheres e grupos desfavorecidos em geral conseguem problematizar abertamente a respeito das desigualdades existentes na esfera privada e, com isso, avançar em conquistas equitativas. Vale ressaltar que a base da legitimidade de propostas na sociedade civil é a busca por direitos, expressos, geralmente, em termos universais. ${ }^{12}$ Existe, portanto, um viés universalista na esfera pública, que abre caminho para conquistas de grupos subordinados ou minoritários.

Uma vez que fomenta discussões públicas, amplia a participação política da sociedade e proporciona, ainda, novas formas de atuação às organizações da sociedade civil, o fortalecimento de instituições deliberativas tende a promover uma redistribuição do poder político. Na verdade, mudanças nas instituições democráticas tendem a confrontar os interesses dos grupos mais beneficiados na institucionalidade vigente. ${ }^{13}$ Com efeito, grupos dominantes frequentemente reagem fortemente diante da criação de procedimentos deliberativos - em especial no caso em que estes atuam em áreas mais abrangentes. Como visto em muitos casos, a criação de tais procedimentos efetua uma inclusão de grupos subordinados, diminuindo, em termos relativos, o poder de grupos então dominantes. Uma vez que os determinantes do subdesenvolvimento se encontram na esfera social e estão vinculados a relações de poder estabelecidas, a criação dessas instituições democráticas adquire grande importância.

Certamente, a democracia deliberativa demonstra ser um mecanismo interessante para o processo de escolha social envolvido na definição das finalidades

11 Ver Ostrom (1996).

12 Ressalvamos que a tradução de direitos de forma excludente pode ser uma pauta promovida por algumas associações da sociedade civil, organizadas em torno da negação de direitos a outros grupos. Esse, no entanto, não parece ser o caso geral e não possui base para legitimidade na sociedade como um todo.

13 Denominados por Evans (2003) de "vencedores institucionais". Segundo o autor, "qualquer conjunto de instituições acarreta uma distribuição de perdas e ganhos” (EVANS, 2003, p. 27). 
do desenvolvimento. Um dos principais desafios refere-se à escala de atuação e à abrangência dos procedimentos já criados. Para tornar possível o exercício de escolha social desejado, é preciso que os procedimentos tenham impacto amplo sobre a atuação estatal, com consequências sobre diversas áreas econômicas e sociais. Além disso, seria preciso levar essas instituições para esferas superiores de tomada de decisão, de modo a envolver a sociedade nacional como um todo. ${ }^{14} \mathrm{~A}$ necessidade de levar tais processos a escalas maiores e mais abrangentes é um dos principais desafios a essas instituições que a nível local apresentam resultados positivos. Vale mencionar, ainda, outros empecilhos ao funcionamento adequado dos procedimentos deliberativos, como a burocratização, a manipulação, a cooptação por grupos dominantes ou a reintrodução do clientelismo, a instrumentalização partidária. Nesse contexto, as organizações da sociedade civil cumprem papel relevante, assegurando, mediante um processo de aprendizado e reflexão crítica, a operação apropriada dos procedimentos.

Em suma, a efetivação de uma trajetória de desenvolvimento endógeno pode ser favorecida a partir da criação de novas instituições democráticas que fomentem o diálogo aberto e a participação política. Trata-se de enraizar as finalidades do desenvolvimento na sociedade civil, levando a administração pública a executar suas funções conforme as escolhas da coletividade, submetendo-se ao controle da maioria da população (HERRLEIN JÚNIOR, 2014). As instituições deliberativas são capazes de, em alguma medida, superar a fragmentação de interesses, fomentando a formulação intersubjetiva de valores e objetivos e permitindo a composição entre os interesses distintos presentes na sociedade. Portanto, a elaboração de procedimentos deliberativos, abertos à experimentação e à criatividade, pode ser compreendida como uma alternativa viável e interessante na promoção do desenvolvimento.

\section{Considerações Finais}

Uma noção mais completa a respeito do desenvolvimento localiza esse fenômeno em uma dinâmica de relações de poder e em certo sistema de estratificação social. Assim, o desenvolvimento deve ser compreendido como histórico de carácter multidimensional, influenciado pela acumulação e delimitado por fatores políticos. A proposta do desenvolvimento endógeno busca traduzir esse processo como meta desejável às sociedades contemporâneas, sendo caracterizado como um projeto aberto definido segundo as prioridades da sociedade. A democracia

14 A abordagem dos sistemas deliberativos apresenta aspectos favoráveis à compreensão da dinâmica e dos empecilhos aos processos de discussão pública em escalas maiores, substituindo a análise de cada procedimento por uma análise sistêmica do processo de constituição da razão pública (MANSBRIDGE et al., 2012). 
adquire um papel essencial nessa concepção. Entretanto, as últimas décadas evidenciaram as limitações dos regimes democráticos contemporâneos em promover a efetiva endogeneização do desenvolvimento, ainda que apresentem resultados sociais favoráveis. Consequentemente, é possível superar os obstáculos existentes mediante a criação de instituições complementares aos regimes representativos, que operem conforme os princípios da democracia deliberativa, visando uma trajetória de desenvolvimento enraizada nos anseios e na criatividade da população.

Há boas razões para se crer que instituições de democracia deliberativa são capazes não apenas de confrontar as forças políticas e o conjunto de relações sociais que sustentam o subdesenvolvimento, mas também de recolocar o esforço da atividade social na perseguição das verdadeiras finalidades do desenvolvimento humano, revertendo a inversão de objetivos protagonizada pela dinâmica da acumulação e sofrida nas sociedades capitalistas de diferentes níveis de desenvolvimento. Portanto, o fomento de instituições deliberativas pode ser considerado um programa válido tanto para o mundo subdesenvolvido, quanto para o desenvolvido. O objetivo é fomentar verdadeiras discussões públicas a respeito de valores, objetivos e estratégias, demarcando democraticamente o perfil das atividades do setor público. As instituições deliberativas apresentam consequências favoráveis ao desenvolvimento, fortalecendo a democracia, provocando redistribuição do poder e certa renovação da sociedade civil e trazendo resultados mais igualitários. Contudo, elas também enfrentam algumas limitações importantes. A principal delas refere-se à escala e à abrangência dos procedimentos, cujas especializações temática e geográfica impõem restrições severas ao debate público sobre os objetivos do desenvolvimento em perspectiva nacional. Um exercício de análise sistêmica da deliberação certamente pode contribuir com essa complexa problemática. Nesse sentido, a criação de procedimentos deliberativos pode ser considerada um mecanismo de qualificação do sistema deliberativo de certa nação democrática.

A deliberação apresenta-se como princípio para orientar a criação de novas instituições democráticas. Não existe um modelo institucional definitivo, e não se pretende defender um conjunto de regras específicas como amplamente generalizáveis. As instituições devem ser contextualizadas na sociedade civil, em um determinado espaço cultural e nos valores difundidos local ou regionalmente. A inclusão de amplas parcelas da população no processo de tomada de decisão pode ser encaminhada também através da experimentação institucional.

A principal questão apresentada é a necessidade de se buscar mecanismos viáveis para a concretização de uma trajetória de desenvolvimento endógeno, recolocando as sociedades contemporâneas no caminho da expansão de suas potencialidades. Tendo isso em vista, este artigo se propôs a enfatizar a relevância dos aspectos políticos e sociais no processo de desenvolvimento, partindo de uma 
abordagem alternativa e reconhecendo as possibilidades de efetivação de tal processo por meio do fortalecimento da participação democrática.

\section{Referências}

AVRITZER, L. Teoria democrática e deliberação pública. Lua Nova, São Paulo, v. 49, p. 2546, 2000.

BAYNES, K. Deliberative democracy and public reason. Veritas, Porto Alegre, v. 55, n. 1, p. 135-163, jan./abr. 2010.

BESLEY, T.; KUDAMATSU, M. Health and democracy.American Economic Review, v. 96, n. 2, p. 313-318, 2006.

CALDWELL, J. Routes to low mortality in poor countries.Population and Development Review, v. 12, n. 2, p. 171-220, 1986.

CORNWALL, A. Participation in development: tracks and traces. Currents, n. 28, p.4-8, Aug. 2002.

DONOVAN, K. Seeing like a slum: towards open, deliberative development. Georgetown Journal of International Affairs, v. 13, n. 1, p. 97-104, 2012.

EVANS, P. Além da "monocultura institucional": instituições, capacidades e desenvolvimento deliberativo. Sociologias, Porto Alegre, v. 5, n. 9, p. 20-63, 2003.

. Government action, social capital and development: reviewing the evidence on synergy. World Development, v. 24, n. 6, p. 1119-1132, June 1996.

. The challenges of the institutional turn: new interdisciplinary opportunities in development theory. In: NEE, V.; SWEBERG, R. (Org.). The economic sociology of capitalist institutions. Princeton: Princeton University Press, 2005. p. 90-116.

EVANS, P.; HELLER, P. Human development, state transformation and the politics of the developmental state. Oxford: Oxford University Press, 2012.

FAGOTTO, E.; FUNG, A. Empowered participation in urban governance: the Minneapolis neighborhood revitalization program. International Journal of Urban and Regional Research, Malden, v. 30, n. 3, p. 638-655, Sept. 2006.

FUNG, A. Accountable autonomy: toward empowered deliberation in Chicago schools and policing. Politics 8 Society, v. 29, n. 1, p. 73-103, Mar. 2001.

. Recipes for public spheres: eight institutional design choices and their consequences. The Journal of Political Philosophy, v. 11, n. 3, p. 338-367, 2003.

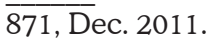

. Reinventing democracy in Latin America.Perspectives on Politics, v. 9, n. 4, p. 857-

FUNG, A.; WRIGHT, E. Deepening democracy: innovations in empowered participatory governance. PoliticsESociety, v. 29, n. 1, p. 5-41, Mar. 2001. 
FURTADO, C. A superação do subdesenvolvimento. In: D’ÁGUIAR, R. (Org.). Essencial Celso Furtado. São Paulo: PenguinClassics Companhia das Letras, 2013b, p. 276-284.

. Análise do modelo brasileiro. 5. ed. Rio de Janeiro: Civilização Brasileira, 1975.

Letras, 2008.

. Criatividade e dependência na civilização industrial. São Paulo: Companhia das . Cultura e desenvolvimento em época de crise. Rio de Janeiro: Paz e Terra, 1984.

. O desenvolvimento do ponto de vista interdisciplinar. In: D’ÁGUIAR, R. (Org.). Essencial Celso Furtado. São Paulo: PenguinClassics Companhia das Letras, 2013a.p. 197-235.

. O mito do desenvolvimento econômico. Rio de Janeiro: Paz e Terra, 1974.

. Pequena introdução ao desenvolvimento: enfoque interdisciplinar. São Paulo: Editora Nacional, 1980.

. Teoria e política do desenvolvimento econômico. São Paulo: Abril Cultural, 1983.

HABERMAS, J. Três modelos normativos de democracia. Lua Nova,São Paulo, v. 36, p. 3953, 1995.

HELLER, P.; HARILAL, K. N.; CHAUDHURI, S. Building local democracy: evaluatingtheimpactofdecentralization in Kerala, India. World Development, v. 35, n. 4, p. 626-648, Apr. 2007.

HERRLEIN JÚNIOR, R. A construção de um estado democrático para o desenvolvimento no século XXI. Brasília, DF: Ipea, 2014. (Texto para discussão, n. 1935).

LUBENOW, J. A. Esfera pública e democracia deliberativa em Habermas. Kriterion, Belo Horizonte, n. 121, p. 227-258, jun. 2010.

MANSBRIDGE, J. et al. A systemic approach to deliberative democracy. In: PARKINSON, J.; MANSBRIDGE, J. Deliberative systems: deliberative democracy at the large scale. Cambridge: Cambridge University Press, 2012.

MARX, K. O capital:crítica da economia política. Livro I. Rio de Janeiro: Civilização Brasileira, 2011.

OSTROM, E. Crossing the great divide: coproduction, synergy, and development. World Development, v. 24, n. 6, p. 1073-1087, June 1996.

RODRIGUEZ, O. O estruturalismo Latino-Americano. Rio de Janeiro: Civilização Brasileira, 2009.

SANTOS, B. S. Orçamento participativo em Porto Alegre: para uma democracia redistributiva. In: SANTOS, B. S. (Org.). Democratizar a democracia: os caminhos da democracia participativa. Rio de Janeiro: Civilização Brasileira, 2002. p. 455-559. 
SANTOS, B. S.; AVRITZER, L. Para ampliar o cânone democrático. In: SANTOS, B. S. (Org.). Democratizar a democracia: os caminhos da democracia participativa. Rio de Janeiro: Civilização Brasileira, 2002. p. 39-84.

SEN, A. Desenvolvimento como liberdade. São Paulo: Companhia das Letras, 2010.

TOUCHTON, M.; WAMPLER, B. Improving social well-being through new democratic institutions. ComparativePoliticalStudies, v. 47, n. 10, não paginado, Dec. 2013.

WAMPLER, B. Instituições participativas como "enxertos" na estrutura do Estado: a importância de contextos, atores e suas estratégias. In: PIRES, R. R. C. (Org.). Efetividade das instituições participativas no Brasil: estratégias de avaliação. Diálogos para o desenvolvimento. v. 7. Brasília: IPEA, 2011, p. 151-158.

WERLE, D. Razão e democracia: uso público da razão e política deliberativa em Habermas. Trans/Form/Ação, Marília, v. 36, p. 149-176, 2013.

Recebido em: 26/12/2016. Aceito em: 27/12/2016. 